\title{
ESTIMATION OF INSTANTANEOUS FIRE FLAMING AND SMOLDERING SIZE TO AMAZON RAINFOREST
}

\author{
Gabriel Pereira ${ }^{l}$, Francielle da Silva Cardozo ${ }^{l}$, Elisabete Caria Moraes ${ }^{l}$, Yosio Edemir Shimabukuro ${ }^{l}$, \\ Saulo Ribeiro de Freitas $^{1}$ \\ ${ }^{1}$ National Institute for Space Research (INPE)
}

\begin{abstract}
Wildfires plays a fundamental intervention in global biogeochemical cycle, by the chemical reaction occurring in the combustion process, and the organic compounds present in vegetation returns to the atmosphere and soil in a cyclical behavior. Therefore, the main objective of this work is to develop a method to estimate the instantaneous fire size in Brazil using Thematic Mapper (TM) aboard of Landsat 5 and Enhanced Thematic Mapper Plus (ETM+) aboard of Landsat 7 . The results indicate that active fire to pastures/grasslands is approximately $38 \%$ higher than that found for forest areas, $31 \%$ higher than the same coefficient used to estimate the fire size in areas of herbaceous and shrub vegetation and $11 \%$ higher than the coefficient used in agricultural areas.
\end{abstract}

Index Terms - South America, Forestry, Remote sensing.

\section{INTRODUCTION}

Wildfire consumes annually large areas of vegetation around the globe and is a noteworthy modifier of terrestrial ecosystems. The anthropogenic burning is essentially linked to agricultural, deforestation, pest control and renovation of pastures and fields activities. However, trace gases and aerosol emissions released from biomass burning, composed primarily by oxidized organic materials, have physical and chemical properties that interact with electromagnetic radiation causing its absorption and scattering. Interactions of radiative active compounds with electromagnetic radiation and changes in land use and land cover cause significant alterations in balance of latent and sensible radiation fluxes, in biogeochemical cycles and in cloud seeding [1].

To understand and model the effects of fires and their role in the biosphere-atmosphere interactions is necessary to know the ground burned area as well as the instantaneous fire flaming and smoldering size, a fundamental parameter to determine the plume injection height originated in combustion process. Moreover, in literature there are some methods to estimate this variable, such as Dozier method [2], which utilizes the bi-spectral approach.

The disadvantages of the method proposed by Dozier [2] is that errors introduced in the process of data acquisition for each band, for example, electronic noise, atmospheric correction, register errors between bands of different spatial resolutions, background temperature estimation, differences in sensitivity, saturation and point spread function can cause variations that could reach $100 \%$ in values [3-5]. Therefore, the main objective of this study is to analyze and estimate the active fire area to different vegetation types from fire radiative power (FRP) calculated by satellites of medium / low spatial resolution.

\section{MATERIAL AND METHODS}

To create a climatological map of instantaneous fire flaming and smoldering size for Amazon Rain forest we randomly sampled 40 path/row of TM Landsat 5 and ETM+ Landsat 7 in Worldwide Reference System (WRS-2) stratified by scenes (Figure 1a) and by distribution of fire radiative power (FRP) derived from MOD14 and MYD14 products for 2000-2010, as shown in Figure 1b. The MODIS fire products, utilize a contextual algorithm applied to brightness temperatures in $4 \mu \mathrm{m}$ and $11 \mu \mathrm{m}$ mid-infrared radiation channels and for each fire detection FRP is calculated. After the determination of each path/row in stratified random sampling, we selected all scenes containing information of the study area. In this step, scenes with cloud cover less than $50 \%$ were selected, resulting in approximately 700 images from Thematic Mapper (TM) aboard of Landsat 5 and Enhanced Thematic Mapper Plus (ETM +) aboard of Landsat 7.

Figure 2 shows the flowchart of the methodology used to estimate the instantaneous fire flaming and smoldering size for South America. In the first stage (I) the TM/Landsat 5 and ETM+/Landsat 7 from 2000 to 2010 were selected and included in the ENVI software, after this step, the band 7, referring to the middle infrared $(2.08$ to $2.35 \mu \mathrm{m})$, was classified selecting the saturated pixels (digital numbers greater than 254). 


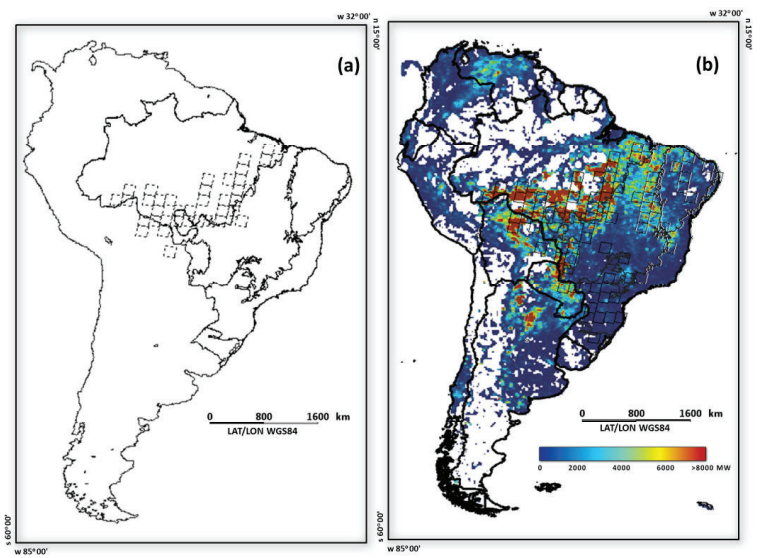

Figure 1. Study area location: (a) Scenes selected by stratified random sampling and (b) Fire Radiative Energy between 2000 - 2010 (MW).

This band was selected due to the sensitivity to high temperatures, since areas in combustion process can reach values greater than $1,700 \mathrm{~K}$, and, according to Wien's displacement law, have maximum emission of electromagnetic radiation at wavelengths below $2 \mu \mathrm{m}$. After classification, the processing of fire flaming and smoldering size was based on simultaneous observation of 1B2G3R, 3B4G5R and classified images. At the end of processing on stage (II) the geographic location (latitude and longitude) of fire, the number of pixels with flaming and smoldering information and land cover (Forest, herbaceous and shrubs vegetation, Grassland and Agriculture) were determined.

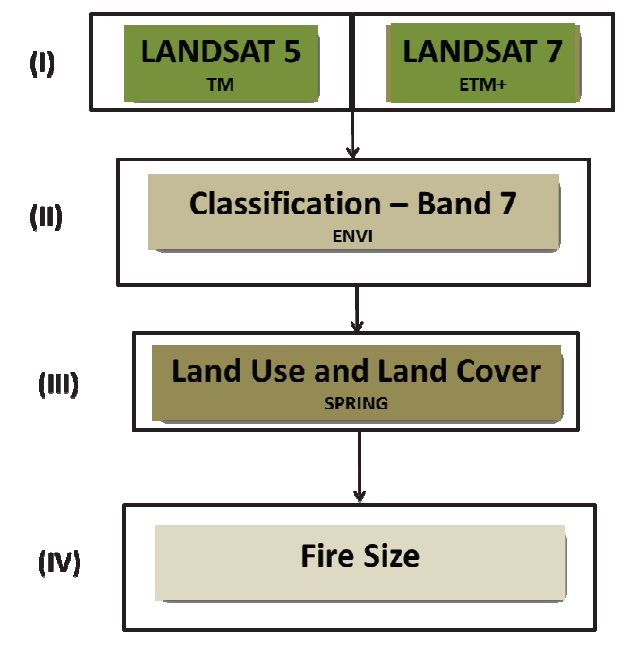

Figure 2. Flowchart of the methodology.

\section{RESULTS AND DISCUSSIONS}

Concerning the results, the highest average values of fire instantaneous area were found in Pasture and Agriculture. In these land use classes, the estimated average is approximately $13,000 \mathrm{~m}^{2}$, however, these land use and land cover differ significantly in relation to the frequency of maximum values, pasture could reach a fire flaming and smoldering size greater than $30,000 \mathrm{~m}^{2}$, but, Agriculture reaches maximum values of $20,000 \mathrm{~m}^{2}$. Moreover, Herbaceous/Shrub vegetation presented values of fire flaming and smoldering size concentrated close to 7,500 $\mathrm{m}^{2}$ (varying from $2,000 \mathrm{~m}^{2}$ to $15,000 \mathrm{~m}^{2}$ ), but some observations could exceed $50,000 \mathrm{~m}^{2}$.

Additionally, Forest classes exhibited a small variation, showing average values of active fire close to $4,000 \mathrm{~m}^{2}$. In this class, the estimated values could vary from $900 \mathrm{~m}^{2}$ to $10,000 \mathrm{~m}^{2}$, but can reach values up to $20,000 \mathrm{~m}^{2}$. Among the categories analyzed, areas of Rainforest had the lowest values of flaming and smoldering size (an average of 3,000 $\mathrm{m}^{2}$ to $7,000 \mathrm{~m}^{2}$ ), and these estimates are related to the fire front, since it is common to find small fire fronts areas in high concentrations of biomass. In contrast, areas of low biomass, such as pasture and grassland, have fire fronts that can reach up to $50,000 \mathrm{~m}^{2}$, since the amount of biomass found in these regions is very low, and factors as wind speed and fire spread to other areas allows a rapidly combustion of above-ground biomass.

Figure 3 show the regression between flaming and smoldering fire size and fire radiative power acquired from MOD14 and MYD14 products from Moderate Resolution Imaging Spectroradiometer (MODIS) and Wildfire Automated Biomass Burning Algorithm (WFABBA) product derived from Geostationary Operational Environmental Satellite (GOES) satellite. The coefficient found for estimating the size of active fire to pastures/grasslands $\left(0.00029 \mathrm{~km}^{2} . \mathrm{MW}^{-1}\right)$ is approximately $38 \%$ higher than that found for forest areas $(0.00021$ $\mathrm{km}^{2} . \mathrm{MW}^{-1}$ ), $31 \%$ higher than the same coefficient used to estimate the fire size in areas of herbaceous and shrub vegetation $\left(0.00022 \mathrm{~km}^{2} . \mathrm{MW}^{-1}\right)$ and $11 \%$ higher than the coefficient used in agricultural areas $\left(0.00026 \mathrm{~km}^{2} . \mathrm{MW}^{-1}\right)$. 

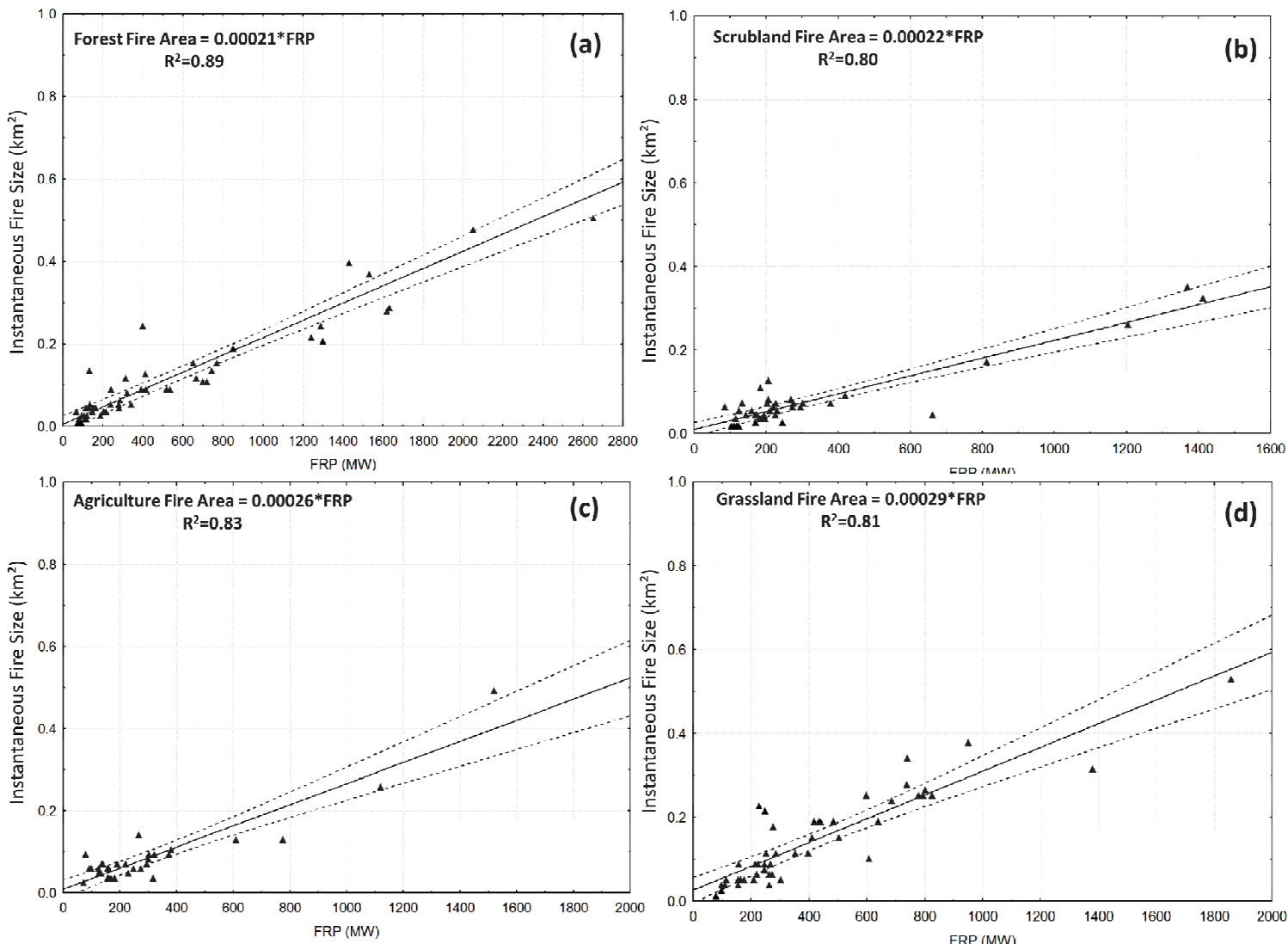

Figure 3. Regressions between instantaneous flaming and smoldering fire size and fire radiative power.

\section{CONCLUSIONS}

Although satellite derived products can estimate active fire area, factors inherent in data acquisition and recording of information can cause significant variations in area calculation. Moreover, sensor sensitivity and saturation coupled with spread point functions and characteristics of each sensor, cause significant errors. Consequently, the development of climatological maps allows estimates of active fire area for the entire globe, which are related to products derived from environmental satellites and weighted by the energy released during the combustion process.

\section{REFERENCES}

[1] Kaufman, Y. J., Tucker, C. J., and Fung, I., Remote Sensing of Biomass Burning in the Tropics, Journal of Geophysical Research, v. 95, n. D7, p. 9927-9939, 1990.
[2] Dozier, J., A method for satellite identification of surface temperature fields of subpixel resolution, Remote Sensing of Environment, v. 11, p. 221-229, 1981.

[3] Giglio, L., Kendall, J., and Mack, R., A multi-year active fire dataset for the tropics derived from the TRMM VIRS, International Journal of Remote Sensing, v. 24, p. 45054525,2003

[4] Wooster, M.J., Roberts, G., Perry, G., and Kaufman, Y.J., Retrieval of biomass combustion rates and totals from fire radiative power observations: calibration relationships between biomass consumption and fire radiative energy release, Journal of Geophysical Research, v. 110, 2005.

[5] Pereira, G., Freitas, S. R., Moraes, E. C., Ferreira, N.J., Shimabukuro, Y.E., Rao, V.B., and Longo, K.M., Estimating trace gas and aerosol emissions over South America: Relationship between fire radiative energy released and aerosol optical depth observations, Atmospheric Environment, v. 43, n. 40, p. 6388-6397. 2009. 